\title{
Mario Góngora como pensador político. Un debate inconcluso
}

\author{
Mario Góngora as a Political Thinker. An Inconclusive Debate
}

Valentina Verbal*

\section{RESUMEN}

Este trabajo tiene un doble objetivo. Por una parte, apunta a

Palabras clave: realizar un balance historiográfico sobre el debate que Mario Mario Góngora, Góngora ha generado en Chile como pensador político, más que como historiador propiamente tal. Y, por otra, cotejar ese debate a la luz de dos ejes fundamentales del pensamiento político de Góngora: antiliberalismo y fascismo católico. Para ello, se distinpensamiento político, antiliberalismo, fascismo católico. guen dos momentos en ese debate: el que siguió a la publicación de su célebre Ensayo histórico sobre la noción de Estado en Chile en los siglos XIX y XX, en la década de 1980, y el libro, editado en 2017 por Gonzalo Geraldo y Juan Carlos Vergara, que da cuenta de unas jornadas sobre el pensamiento de Góngora, celebradas tres años antes. El argumento de este artículo es que la mayoría de los comentaristas de Góngora tiende a pasar por alto o, al menos, minimizar los mencionados ejes de su pensamiento, lo que ha generado una notoria condescendencia hacia su figura intelectual.

\begin{abstract}
This paper has a two-fold aim. On the one hand, its purpose is to perform a historiographic assessment of the debate generated by Mario Góngora in Chile, focusing more in his figure as a political thinker than as a mere historian. And, on the other hand, it seeks to review this debate considering two core pillars of Góngora's political thought: anti-liberalism and Catholic fascism. To do so,
\end{abstract}

Keywords: Mario Góngora, political thought, anti-liberalism, Catholic fascism.

Chilena. Licenciada en Historia, Universidad de los Andes, Chile, y Magíster en Historia de la Universidad de Chile. Becaria Fulbright, estudiante del Programa de Doctorado en Historia Atlántica, Florida International University, Estados Unidos. E-mail: vverb001@fiu.edu La autora agradece los generosos comentarios de Benjamín Ugalde, Felipe Schwember y de los evaluadores de la revista. 
it distinguishes two moments in this debate: that following the publication of his famous Ensayo histórico sobre la noción de Estado en Chile en los siglos XIX $y X X$, in the 1980s, and the book edited in 2017 by Gonzalo Geraldo and Juan Carlos Vergara, which presents reflections on Góngora's ideas. This article argues that most commentators on Góngora tend to overlook or, at least, minimize the abovementioned core pillars of his political thought, which has generated a notorious condescendence towards his figure as an intellectual. 
Mario Góngora del Campo (1915-1985) fue un destacado historiador chileno que abrió la disciplina historiográfica hacia nuevas tendencias, más allá de la historia política tradicional, cuyo enfoque era meramente descriptivo en su mayoría. Gabriel Salazar - quien fuera su alumno y ayudante- señala que el aporte de Góngora no se reduce únicamente a la circunstancia de trabajar documentación desde los archivos - cosa que ya hacían otros historiadores-, sino que también se amplía al intento de forjar "una visión hermenéutica de los hechos y las situaciones que iba encontrando en la investigación, lo que lo llevó al ejercicio [...] de construir conceptos, a partir de los datos o información dura que uno encuentra" (Salazar, 2017: 35).

Pero la relevancia de Góngora no se agota en su calidad de historiador, sino que se extiende también a su carácter de pensador político. Pese a que él fue especialmente un colonialista, fue a la vez un activo protagonista de los debates públicos que se dieron en Chile entre los años 30 y 80 del siglo pasado. ${ }^{1}$ En efecto, en su juventud fue una suerte de "ideólogo" de la Juventud Conservadora en Chile, antecedente directo de la Falange Nacional, movimiento político muy influido por la Falange española, fundada y liderada por José Antonio Primo de Rivera (1903-1936). ${ }^{2}$

Más adelante, y sobre todo desde 1945, Góngora se concentrará en su carrera académica como profesor en la Universidad de Chile y, sobre todo, orientará sus energías intelectuales a producir la que sería su gran obra historiográfica. ${ }^{3}$ Pero mientras hacía aquello, se mantuvo siempre firme en la defensa de sus ideas políticas.

En 1981, pocos años antes de su muerte, publicó un trabajo que causó gran impacto y polémica entre los historiadores chilenos, pero también entre otros académicos e intelectuales públicos; se trata del

En cuanto a su obra historiográfica, Góngora escribió no solo sobre Chile, sino sobre temas más amplios en el contexto de Hispanoamérica. Ver, para el caso de Chile, Góngora (1970) y, para Latinoamérica, Góngora (1975).

2 Por ejemplo, pronunció uno de los discursos principales de la Convención la Juventud Conservadora, en 1937. En dicho discurso ya expresaba una visión contraria al liberalismo económico, sobre la que volverá más tarde, durante el régimen de Pinochet: "Una economía comunitaria debe tender a suprimir la división del capital y el trabajo, que comenzó a fines de la Edad Media, y dar a la clase proletaria su rol de elemento principal, eficiente, creador de la producción". Citado por Arancibia Clavel (1995: 128).

3 Para un acercamiento breve a su obra historiográfica, ver Yávar Meza (2017: 51-60). 
Ensayo histórico sobre la noción de Estado en Chile en los siglos XIX y $X X$, conocido simplemente como Ensayo histórico (Góngora, 1981). ${ }^{4}$ Además de discutirse su visión de la historia de Chile durante la República, se hizo lo propio con sus ideas políticas. Por ejemplo, y ya en la última parte referida a la dictadura de Augusto Pinochet (1973-1990), Góngora valoró el golpe de Estado del 11 de septiembre de 1973 por tener, para él, un carácter tradicionalista y tomista. ${ }^{5}$ Pero, sin cuestionar el carácter autoritario del régimen ni las graves y sistemáticas violaciones a los derechos humanos a que este dio lugar, sus críticas se centraron en la implantación de un sistema económico "neoliberal", basado en las ideas de autores como Friedrich Hayek y Milton Friedman (Góngora, 1981: 132-138). Como es sabido, el régimen de Pinochet aplicó políticas de apertura económica, como el fomento del comercio exterior, la libertad de precios, la privatización de empresas estatales, etcétera. En Chile, además, ejercieron gran influencia en la implementación de tales políticas un grupo de economistas - conocidos como Chicago Boys - que estudiaron maestrías o doctorados en la Universidad de Chicago, con profesores como Arnold Harberger y el mismo Milton Friedman, entre varios otros. ${ }^{6}$

Pero, más allá de ese punto específico, lo cierto es que, a más de treinta años de su muerte, la figura de Góngora sigue hoy generando apasionados debates. $\mathrm{Y}$ esto por razones diversas: por su interpretación de la historia de Chile (en torno a distintas épocas y temas), pero también por sus ideas políticas, expresadas en distintos momentos de su vida, aunque de un modo emblemático durante el régimen de Pinochet. En años recientes se han publicado varios estudios sobre Góngora, pero mayoritariamente en el terreno historiográfico, por ejemplo, en torno a su filosofía de la historia de corte spengleriano. ${ }^{7}$ Además, y

\footnotetext{
4 Por recomendación de uno de los evaluadores, sigo la primera edición de esta obra, que se encuentra disponible en el sitio www.memoriachilena.cl. Pero valga aclarar que, luego, desde su segunda edición, el Ensayo histórico comenzó a ser editado por la Editorial Universitaria, perteneciente a la Universidad de Chile.

5 Dice Góngora: "En cuanto a la Declaración de Principios [del régimen militar] no cabe duda de que extrae su inspiración del tradicionalismo español y más generalmente, de la concepción tomista, en cuya virtud la finalidad suprema del Estado es la idea del bien común, que es más que la suma de intereses particulares" (Góngora, 1981: 133).

6 Como fuentes testimoniales de esta influencia, ver Arancibia Clavel y Balart Pérez (2007); y Soto y Sánchez (2015).

Ver, por ejemplo, Góngora Escobedo (1990: 39-79).
} 
como fuentes primarias, se han editado conferencias y ensayos en revistas de pensamiento político, su tesis de licenciatura y, de manera especial, su diario de vida, que es principalmente (aunque no de manera exclusiva) un diario intelectual. ${ }^{8}$ A través de esta última fuente, puede apreciarse a Góngora como un lector empedernido, especialmente en torno a obras literarias, históricas y, en el terreno político, de autores tradicionalistas y nacionalistas.

El presente trabajo tiene un doble objetivo. Por una parte, hacer un balance historiográfico sobre algunos debates que Góngora ha generado como pensador político más que como historiador. Y, cuando se considere esta última calidad, se hará únicamente en la medida en que ello da cuenta de sus ideas políticas. Quizás sea Góngora unos de los autores más citados por los historiadores en Chile, por sus aportes en diversas temáticas de la historia de este país y de Hispanoamérica, en particular en la historia colonial. Pero aquí - cabe reiterar- se destacará fundamentalmente su calidad de pensador político. Como segundo objetivo, y desde los debates referidos, este trabajo argumentará que el pensamiento político de Góngora tiene dos ejes fundamentales: a) antiliberalismo, incluyendo aquí su rechazo a la democracia representativa y a la economía de libre mercado, y b) fascismo católico, lo que se expresa en una mixtura entre tradicionalismo y corporativismo. Mientras el primer eje responde - podría decirse - a la dimensión o faceta reaccionaria de su pensamiento político, el segundo hace lo propio con la dimensión o faceta propositiva de ese mismo pensamiento.

Este trabajo distinguirá dos grandes fases o momentos claves en torno al debate que la figura de Góngora - en cuanto pensador político- ha generado. El que se dio después de la publicación de su Ensayo histórico (durante la década del 80), y el que se expresa en el reciente libro, editado por Gonzalo Geraldo y Juan Carlos Vergara, Mario Góngora: el diálogo continúa (2017).

En el primero de esos momentos el debate se centró sobre todo en su interpretación de la historia de Chile contenida en el Ensayo histórico. Aunque fue un debate más bien historiográfico, tuvo sin embargo algunos ribetes de corte político, que vale la pena considerar, y que se

Ver, respectivamente, Góngora (1987, 2016 y 2013). 
vinculan especialmente a la tesis de Góngora, según la cual sería el Estado el que, a lo largo de la historia de Chile, habría creado la nación. Asimismo, y como una aplicación concreta de esta tesis, aquí se discutió su visión crítica del régimen de Pinochet, especialmente por su giro liberal en materia económica.

Por su parte, el segundo momento - expresado en la obra editada por Geraldo y Vergara- es mucho más rico en cuanto a considerar a Góngora como pensador político. Intervienen en esta obra doce autores - entre historiadores, filósofos e intelectuales de diversas tendencias políticas-y puede ser calificada como una suerte de "consagración" de Góngora como una figura intelectual de carácter transversal, ya que ha terminado generando adhesión o simpatía en intelectuales de las más variadas tendencias políticas.

Sin embargo, con relación a ambas fases, no deja de llamar la atención que los autores que han tratado a Góngora se refieran muy de pasada al contenido de fondo de sus ideas políticas. Lo que más bien hacen es discutir el posicionamiento de Góngora ante la política contingente y, especialmente, ante la dictadura de Pinochet. Y aunque tales autores discuten algunas de sus ideas, no entran en profundidad a los elementos que, a juicio de esta autora, caracterizan de manera fundamental su pensamiento político: antiliberalismo y fascismo católico.

Por tener un carácter reaccionario o por sustentarse en una suerte de "enemigo común", no resulta fácil definir la categoría antiliberalis$m o$. Sin embargo, se trata de una categoría cuya existencia no es tan difícil de demostrar. Un autor que la ha trabajado de manera monográfica es Stephen Holmes (1993) en The Anatomy of Antiliberalism, que se concentra en el antiliberalismo no marxista o de derechas, dejando de lado el marxista o de izquierdas, mucho más estudiado. ${ }^{9}$ Dos puntos claves de este antiliberalismo son: a) el sentimiento de decadencia cultural, y b) la crítica a un supuesto atomismo social. Tales puntos, como se verá, se encuentran muy presentes en Góngora.

\footnotetext{
9 Por cierto, no todo antiliberalismo de izquierdas es marxista, pero al menos podría sostenerse que el rechazo al libre mercado, al mismo tiempo que se minimizan otros elementos - como el autoritarismo y el corporativismo-, tiene en el marxismo una base de apoyo fundamental en términos intelectuales. Este hecho, como se ha indicado más arriba, puede ayudar a explicar el carácter transversal que la figura de Góngora ha generado en autores de las más diversas tendencias políticas.
} 
¿Y qué podría decirse del fascismo católico, la cara afirmativa del pensamiento político de Góngora? La tesis de este trabajo es que, aunque en principio no resulte fácil calificar a Góngora como "fascista" (especialmente por la carga peyorativa en la que ha derivado esta palabra), el término "fascismo" es una categoría ideológica fundamental en el contexto del siglo XX, y que tiene algunas características específicas que deberían considerarse. Pero, además, aquí se destacará un fascismo específico - el católico-, especialmente de raigambre española. Este fascismo, historiográficamente estudiado por Stanley Payne (1985), suele alimentarse de dos componentes fundamentales: tradicionalismo y corporativismo.

Como se verá más adelante, la condescendencia que invariablemente tienen los historiadores chilenos para con el pensamiento político de Góngora se puede explicar por su antiliberalismo integral, es decir, por su antiliberalismo político, económico y cultural. Mientras el primero y el tercero hacen que Góngora termine siendo muy valorado por autores conservadores, el segundo explica que sea valorado por sus intérpretes de tendencia socialista. Quizás aquí radique la causa de que prácticamente nadie analice a fondo (y problematice) el antiliberalismo de Góngora. Y aunque algunos autores buscan penetrar en sus ideas, utilizan categorías que, si bien se encuentran presentes en ellas - como la de estatismo-, no constituyen el quid de su pensamiento, sino que dan cuenta de elementos accesorios, que derivan de los dos ejes (ya mencionados) de su pensamiento político. ${ }^{10}$

\section{El Ensayo histórico. Las coordenadas de un debate político}

Como se ha dicho, no es este el lugar para referir en detalle la interpretación historiográfica de Góngora, que puede leerse en su Ensayo histórico. Sin embargo, sí resulta necesario resumir la tesis general del libro, puesto que ella ha propiciado un cierto acercamiento a sus ideas políticas. Además, gracias a esa misma tesis, es posible penetrar más

\footnotetext{
10 Dicho sea de paso, la categoría estatismo no dice mucho del pensamiento político de un autor, cualquiera que éste sea, puesto que se encuentra presente, por ejemplo, tanto en el socialismo como en el fascismo. De ahí que resulte necesario acudir a categorías ideológicas más precisas.
} 
a fondo en esas mismas ideas, concretamente en su antiliberalismo y fascismo católico.

Señala Góngora:

"La idea cardinal del Chile republicano es, históricamente considerado, que es el Estado el que ha ido configurando y afirmando la nacionalidad chilena a través de los siglos XIX y XX; y que la finalidad del Estado es el bien común en todas sus dimensiones: defensa nacional, justicia, educación, salud, fomento de la economía, protección de actividades culturales, etcétera" (Góngora, 1981: 134).

Desde esta perspectiva, lo que Góngora lamentará del régimen de Pinochet es que, al introducir un modelo de libre mercado, el Estado dejaría de jugar un rol fundamental en la vida de las personas, pasando a desempeñar un papel meramente subsidiario. Tan grande será este lamento que, ya en el prefacio a la primera edición del Ensayo históri$c o$, confiesa que:

"Los ensayos sobre el Estado Nacional Chileno que he reunido en este volumen tuvieron su origen en los sentimientos de angustia y de preocupación de un chileno que ha vivido la década de 1970 y 1980, la más crítica y grave de nuestra historia. Estos sentimientos me han forzado a mirar y a reflexionar sobre la noción del Estado, tal como se ha dado en Chile, donde el Estado es la matriz de la nacionalidad: la nación no existiría sin el Estado, que la ha configurado a lo largo de los siglos XIX y XX" (Góngora, 1981: 5).

Esta es la tesis más importante de su trabajo que, a su vez, generará un importante debate, al poco tiempo de ser publicado. Desde un punto de vista historiográfico, la gran pregunta planteada en ese momento fue si es cierto que, después de la Independencia - conquistada en 1818-, el Estado chileno creó la nación. ¿Acaso no existía la nación antes? ¿No poseía Chile ya una identidad colectiva, forjada desde España durante los siglos coloniales?

Una respuesta positiva a esa interrogante había sido planteada mucho antes por Jaime Eyzaguirre (1908-1968), uno de los principales historiadores y pensadores chilenos calificados de "hispanistas", no porque se especializase en la historia de España, sino por hacer una interpretación de la historia de Chile a partir de una valoración positiva de la cultura española, especialmente desde los tiempos de la Con- 
quista. ${ }^{11}$ Desde de esta misma corriente de pensamiento, Bernardino Bravo Lira hace ver la continuidad entre el Estado indiano del despotismo ilustrado y el Estado portaliano, consagrado en la Constitución de 1833. Esta continuidad se explica, insinúa Bravo, no solo en términos institucionales, sino también en una determinada cultura social y política, que se remonta a los siglos de dominación española (Bravo Lira, 1992).

Pero esa tesis general de Góngora - que sostiene que el Estado crea la nación- tendrá también repercusiones en el terreno político. Será sobre todo Arturo Fontaine Talavera quien la cuestionará con más fuerza. En un artículo publicado en la revista Economía y Sociedad, Fontaine pondrá en entredicho la tesis de Góngora, no solo en términos historiográficos, sino sobre todo en términos políticos. Y aunque considera que el Ensayo histórico es un libro importante, cuestiona el argumento según el cual la originalidad de Chile derivaría del hecho de que el Estado habría creado la nación, especialmente a partir de distintas guerras: Independencia (1814-1818), contra la Confederación Perú-boliviana (1837-1839) y del Pacífico (contra una alianza peruanoboliviana, otra vez, entre 1879-1884). ${ }^{12}$ Señala Fontaine: "La primera pregunta que cabe es ¿en qué países no ha sido así y por qué?". Y añade: "Así, por ejemplo, a mi juicio, las implicancias de la tesis quedarían más claras si el autor explicara qué diferencias relevantes hay respecto de otros Estados que, como el de los Estados Unidos, también parece haber gestado una nación, y a partir de un conjunto de naciones bastante disímiles" (Fontaine, 1982).

En segundo lugar, Fontaine hace ver que no queda claro si Góngora quiere dar cuenta de la historia del Estado como concepto, como ha sido entendido a lo largo del periodo republicano en Chile, o del Estado como institución, "tal como se ha dado en los siglos XIX y XX". Pero, además, señala Fontaine, lo que Góngora entiende por Estado no es lo

\footnotetext{
11 Por ejemplo, en una importante obra suya, publicada originalmente en 1957, Eyzaguirre busca demostrar que las ideas políticas que inspiraron la Independencia chilena fueron en gran medida españolas más bien que americanas o francesas (Eyzaguirre, 2002). Este punto ha sido discutido - o, al menos, matizado - por Collier (1977).

12 Dice Góngora: "La imagen fundamental y primera que se tiene de Chile es que constituye, dentro del Imperio español, en las Indias, una frontera de guerra, una 'tierra de guerra"' (1981: 7). Luego desarrolla esta idea haciendo referencia a las guerras indicadas en el párrafo que da lugar a esta nota.
} 
que todo el mundo entiende por tal. Esto sería así por el historicismo que alimenta el ensayo de Góngora, "y en virtud del cual se relega a segundo lugar el análisis sistemático, y se usan poco o nada los análisis teóricos o conceptuales" (Fontaine, 1982).

Lo anterior es importante porque Góngora, en línea con su pensamiento político, busca identificar el Estado con la sociedad. De hecho, cuando define el Estado lo hace a partir de dos autores. Señala, con Edmund Burke (1729-1797), que el Estado es un contrato "entre los que están vivos, los que han muerto y los que nacerán". Luego, siguiendo a Spengler, agrega que el "verdadero Estado es una unidad de existencia histórica" (Góngora, 1981: 5). En ambos casos, dice Fontaine, "la noción de Estado no queda suficientemente definida como objeto central de este ensayo". Pero, respecto del primero, indica que "Burke se refiere [...] más bien a la sociedad que al Estado, la cual, en su opinión, es un contrato permanente" (Fontaine, 1982).

Por otra parte, la noción gongoriana de Estado resulta ad hoc para la defensa de un orden social autoritario y corporativo, más que liberal y democrático. De hecho, en la réplica que le hace a Fontaine, Góngora aclara que no distingue de manera tajante entre Estado y sociedad, que el Estado puede ser la expresión de la sociedad misma. Y agrega, para apoyar su argumento, que el mismo Burke no contrapone el Estado a la sociedad; que esta distinción será decimonónica, teniendo a Hegel como a uno de sus principales artífices. Pero, más importante que ello, Góngora afirma que "el Estado es una idea de totalidad, en el sentido de un Ranke, o de los románticos, o del idealismo, que es en el fondo la idea tradicional de Estado, que viene desde Grecia, de la polis, de Platón y Aristóteles" (Góngora, 1982).

Es decir, Góngora descarta la distinción moderna - y fundamental para el liberalismo - entre Estado y sociedad civil, y adhiere en su lugar a una concepción orgánica del Estado, muy similar a la del fascismo católico, representado en España por la Falange y, posteriormente, por el régimen franquista, según la cual la sociedad se asemeja a un cuerpo viviente, a partir del cual las personas y grupos sociales cumplirían "funciones naturales".

Es importante aquí aclarar que, incluso en su misma época fundacional, la Falange española se sentía parte del gran movimiento 
fascista de Occidente. De acuerdo con Chris Bannister, lo que hizo Primo de Rivera fue hispanizar el fascismo italiano, mediante una síntesis entre ideas fascistas originarias - desarrolladas por Mussolini y Gentile - y algunas creencias del tradicionalismo español (Bannister, 2012: 92). Cuando la Falange española fue fundada en 1933, Primo de Rivera creía que España se encontraba en una crisis o en decadencia, por haber perdido su destino histórico (Bannister, 2012: 95). Al mismo tiempo, llegó a concluir que el despliegue de la libertad que propugna el liberalismo - el derecho a perseguir un destino individual- puede afectar los valores culturales tanto de Europa como de España (Payne, 1985: 49). Es interesante constatar que una visión muy similar a esta atravesó toda la vida intelectual de Góngora y que, incluso, se encuentra presente en su Ensayo histórico.

Otro comentario interesante del libro de Góngora provino de Gabriel Salazar, quien publicó una reseña en la revista Nueva Historia, fundada en Inglaterra por algunos historiadores chilenos exiliados, quienes cursaban allí sus estudios de doctorado. En esta reseña, Salazar reconoce que los historiadores deben participar e iluminar los grandes debates que se dan en el espacio público. Considera que el género "ensayo histórico" ha sido una excelente vía para esa participación de parte de una importante lista de historiadores. "Todos los 'ensayos' escritos por estos autores - que ejercieron en su tiempo una considerable influencia formativa sobre los distintos sectores de la opinión pública - trabajaron lo que podría llamarse 'el sentido' de la historia de Chile" (Salazar, 1982: 193). De esta manera, y luego de varios años de ausencia de este género, "Góngora rompe medio siglo de silencio social de los historiadores chilenos, saca por fin una voz históricamente sabia a plena luz del día, abre las ventanas de la 'caverna platónica' colonial, restaura la función social -más académica- de los 'ensayos históricos' e incita al debate nacional a tomar verdadera altura, es decir, a retornar a lo que es propio" (Salazar, 1982: 197).

Y aunque, como constata el mismo Salazar (1982: 197), Góngora dedica muy pocas páginas a la dictadura militar de Pinochet, no cabe duda de que el tratamiento de ese periodo llama la atención, por haberse escrito durante la vigencia del mismo régimen y, sobre todo, por dar cuenta de una crítica de un autor no precisamente de izquierdas. Sin embargo, el conjunto de la obra —su interpretación de los siglos 
XIX y XX - constituye una respuesta a la angustia que el mismo Góngora confiesa padecer como consecuencia del momento que Chile vivía bajo Pinochet. Nuestro pensador busca demostrar que el Estado ha sido el gran artífice de la nación o sociedad chilena, y que el régimen de Pinochet estaría rompiendo con esa tradición, al instaurar un modelo que tiende al atomismo social y a la pérdida de un horizonte común de sentido. Sin embargo, y como se ha dicho, el problema para Góngora no es la existencia de un régimen autoritario o la violación de los derechos humanos, sino la instauración del libre mercado, que haría que la población se vuelva egoísta y materialista.

No obstante estos flancos, Góngora terminará siendo valorado por autores de las más diversas tendencias políticas, incluyendo al mismo Salazar. ${ }^{13}$ Probablemente, el economicismo que alimenta al marxismo (la democracia y los derechos humanos, para esta ideología, son parte de la superestructura que buscaría justificar las relaciones de producción) ayude a explicar la complacencia con la que Góngora es recibido entre autores de tendencia socialista ${ }^{14}$.

Una tercera aproximación interesante al pensamiento político de Góngora, durante los años posteriores a la publicación del Ensayo histórico, puede encontrarse en Marcos García de la Huerta. En 1987, a través de la revista Opciones, García de la Huerta señala que la idea gongoriana de que el Estado crea la nación tiene algo de sentido. Afirma que las elites chilenas que construyeron la república, emblemáticamente representadas por el ministro Diego Portales (1793-1837) — de la cual, precisamente, se deriva la expresión "Estado portaliano" - , necesitaban de la noción de un Estado autoritario por tres razones fundamentales: a) por ser "la única que no ocasionaría una ruptura total con el pasado hispano-monárquico"; b) por "procurarle a la república recién nacida un estatuto jurídico-político" que le permitiera ser tratada igualitariamente por los demás estados, especialmente España, y c) "evitar la pugna intestina que desangraba a repúblicas 'hermanas' e instaurar una nueva legalidad" (García de la Huerta, 1987: 157).

13 Lo que no quita que Salazar haga sus matices. Uno de ellos, y muy importante, es el siguiente: "El profesor Góngora no logra escapar del todo al embrujo portaliano, ni romper la tendencia tradicional a considerar sus ideas de poder como el referente absoluto para toda la historia nacional" (1982: 197).

$14 \quad$ Ver el Manifiesto comunista, publicado originalmente en 1848. 
Sin embargo, García de la Huerta evalúa críticamente esta visión. Primero, indica que la República de Chile surgió de un proceso de adaptación-falsificación de la democracia estadounidense, y que el resultado de esto fue que, en realidad, no cumplió con la promesa de construir un Estado liberal y democrático, como sí ocurrió en el país del norte (García de la Huerta, 1987: 157). En otras palabras, Chile habría quedado atrapado "en su pasado autoritario, aristocrático y católico, sin conseguir llenar el vacío que dejó [...] su antirracionalismo, la proscripción de la Reforma, su resistencia a la Ilustración y a la Revolución Industrial" (García de la Huerta, 1987: 158). No son muchos los autores, valga decir, que plantean la idea de que la construcción del Estado en Chile, durante la época posterior a la Independencia, se realizó en oposición a los principios del liberalismo y de la democracia.

Otro elemento que García de la Huerta pone sobre la mesa guarda relación con el hecho de que nuestro pensador formaría parte de una historiografía "politocéntrica", que pone al Estado como el eje central de la vida social, y que tiende a subordinar, bajo su poder, al pueblo y a la nación. “Pero 'el pueblo', la nación en general también existe, aunque no adquiera aún plena identidad política” (García de la Huerta, 1987: 159). Dicho de otra forma, este autor insinúa que la visión de Góngora apunta a la subordinación del pueblo o nación al Estado, desconociendo la vida que se genera desde abajo hacia arriba.

Por último, y ahora entrando más directamente al pensamiento político de Góngora, García de la Huerta constata que su célebre sentencia - "El Estado crea la nación" - proviene del filósofo italiano Giovanni Gentile (1875-1944), conocido como "filósofo del fascismo", quien señala, haciendo un doble juego: "Se la nazione crea lo stato, lo stato crea la nazione."${ }^{\prime 15}$ Pero, añade, la idea que expresa esa sentencia puede también encontrarse en el pensamiento de Carl Schmitt (18881985) (García de la Huerta, 1987: 160). Aunque García de la Huerta no profundiza en esta última conexión, cabe señalar que Schmitt sostiene que la reunión del pueblo, salvo que se trate de un grupo de interés, "sea en manifestaciones callejeras, en fiestas públicas, en teatros, en el hipódromo o en el estadio", implica que ese pueblo se convierte, "al menos potencialmente, [en] una entidad política” (Schmitt, 1982: 160).

$15 \quad$ Énfasis en el original. 
En otras palabras, en Schmitt - así como en Góngora y Gentile- puede perfectamente el pueblo (la sociedad o la nación) llegar a identificarse con el Estado.

Conviene reiterar que el antiliberalismo de Góngora se alimenta, de modo particular, de la consideración de que el libre mercado (y también la democracia representativa, basada en el voto individual) tiende a la atomización de la sociedad y a la pérdida de su carácter orgánico. En su respuesta a Fontaine, Góngora sostiene que, a diferencia del tomismo y del aristotelismo, "el neoliberalismo viene de siglos e inspiraciones totalmente diferentes: lo que el tomismo llama bien común no es la suma de bienes particulares, sino un bien específico y orgánico" (Góngora, 1982). Es decir, lo que él rechaza con más fuerza del liberalismo es el hecho de que busque legitimar el individualismo político; la circunstancia - en palabras de Juan Ramón Rallo- de colocar al individuo "en una posición privilegiada frente al resto del orden político: en una posición de soberanía sobre sí mismo" (2019: 16). Este principio, no sólo liberal, sino propio de la modernidad, resulta inadmisible para Góngora.

\section{¿El diálogo continúa? Góngora en el siglo XXI}

La segunda fase que, en el marco de este trabajo, se ha identificado como relevante en el debate sobre Mario Góngora, puede situarse en el libro editado por Gonzalo Geraldo y Juan Carlos Vergara, y que lleva por título Mario Góngora: el diálogo continúa. Once reflexiones sobre su obra. Aunque este trabajo fue publicado en 2017, da cuenta de unas jornadas de discusión sobre la figura de Góngora, que se extendieron entre abril y diciembre de 2014. Contiene algunas aproximaciones interesantes al pensamiento político de Góngora, aunque sin profundizar demasiado en los ejes fundamentales del mismo: antiliberalismo y fascismo católico.

Alejandro San Francisco aborda una cuestión que, sin lugar a dudas, constituye un aporte de Góngora en términos historiográficos y que, a la vez, se conecta con sus ideas políticas: la circunstancia de que él haya incorporado algunos conceptos fundamentales en la interpretación de la vida republicana en Chile, elemento también indicado por Salazar, como vimos más arriba. Uno de esos conceptos es la noción de "tiempo de caudillos", para referirse a los liderazgos personalistas de 
Arturo Alessandri Palma y Carlos Ibáñez del Campo, que gobernaron Chile entre 1920 y 1932 (San Francisco, 2017: 72).

Otro concepto, quizás más relevante para el debate político que la figura de Góngora ha generado, es el de "planificaciones globales”, que utiliza para referirse a los gobiernos de Eduardo Frei Montalva (Democracia Cristiana: 1964-1970), Salvador Allende (Unidad Popular: 19701973) y Augusto Pinochet (dictadura o régimen militar: 1973-1990) (Góngora, 1981: 126-138). Aunque Góngora no define expresamente el concepto de "planificaciones globales", sí insinúa su sentido. Gonzalo Vial Correa (1930-2009) señala que se refiere a "la adopción de un 'modelo' específico de sociedad, que cubre todos sus aspectos; no sólo políticos, sino sociales, económicos, educacionales, culturales, internacionales, etcétera, sin excluir ninguno" (Vial Correa, 2009: 1256).

Como se ha indicado, uno de los puntos que más interés ha despertado entre los estudiosos de Góngora es su referencia crítica al gobierno de Pinochet, por haber abandonado el papel protagónico del Estado en la configuración de la nacionalidad chilena. En una entrevista a la periodista Rosario Guzmán, profundiza en esta idea: "A mi juicio, el neoliberalismo ha socavado las esperanzas concebidas el 11 de septiembre [de 1973, fecha del golpe de Estado], y las bases políticas tradicionales [tomistas] del régimen surgido en esa jornada". Y agrega: "Gobernando conforme a una receta teórica, haciendo tabla rasa de la idiosincrasia y del carácter nacional, suprimiendo el rol mediador del Estado en los conflictos sociales, ha dejado a las clases sociales frente a frente" (Guzmán, 1982: 25).

Otro punto interesante que aborda San Francisco es la crítica más específica que Góngora le formula al régimen de Pinochet en lo que al concepto de "subsidiariedad" se refiere. Según Góngora, mientras que en la Declaración de Principios del Gobierno Militar (1974) ese concepto apuntaba "a proteger una concepción orgánica del Estado" (Góngora, 1981: 134), con la "revolución desde arriba" del neoliberalismo ha devenido en una franca "tendencia anti-estatal" (Góngora, 1981: 136). San Francisco sostiene que la noción de “subsidiariedad", de la cual da cuenta nuestro pensador — que se refiere a la primacía y autonomía de los cuerpos intermedios frente al Estado-, si bien es correcta, no representa la amplitud que ella admite. "Adicionalmente, también había otras fuentes del pensamiento económico, aunque 
a la larga confluyeron con el gremialismo que era el principal difusor de la subsidiariedad, por medio de su líder Jaime Guzmán" (San Francisco, 2017: 83-84). ${ }^{16} \mathrm{Y}$ agrega el hecho de que Góngora omite que el giro del gobierno militar hacia un modelo liberal en términos económicos se explica no solo por razones de carácter doctrinal, sino más bien pragmáticas, asociadas al fracaso de un sistema económico basado en "un estatismo absorbente y con resultados precarios" (San Francisco, 2017: 84).

Un segundo planteamiento interesante, en el marco del libro editado por Geraldo y Vergara, está representado por Rodrigo Karmy. Señala Karmy que el Ensayo histórico de Góngora da cuenta de "la matriz teológico-política de toda historiografía, en su función sancionadora y en la escenificación tribunalicia en la que se despliega su discurso". Dicho de otra forma, agrega Karmy, la obra en cuestión de Góngora "puede leerse como teología política de corte apocalíptico". ${ }^{17} \mathrm{Y}$, concretamente, su enjuiciamiento daría cuenta de "la crisis del Estado y el consecuente advenimiento de la dispersión, al caos y el nihilismo en la forma de despolitización neoliberal" (Karmy, 2017: 100).

Pareciera que Karmy siente simpatía por ese diagnóstico de Góngora. Así parece porque no hay, por su parte, ningún cuestionamiento a las ideas de fondo en que tal diagnóstico se inspira: ideas antiliberales, no solo en términos económicos, sino también desde un punto de vista político. Góngora, como ya se ha visto, no creía en la democracia representativa, sino en regímenes autoritarios y corporativos. Al mismo tiempo, Karmy pasa por alto la otra sentencia que Góngora dicta: aquella mediante la cual saluda como un hecho positivo el golpe de Estado de 1973, que derrocó al gobierno de Allende, por haberse basado en principios tradicionalistas. Karmy, sin embargo, subraya que Góngora no critica simplemente el "Golpe de Estado", que las fuerzas armadas de Chile lideraron, sino el "Golpe al Estado como tal", que el gobierno posterior, encabezado por Pinochet, llevaría a cabo. "Tal Golpe habrá sido el origen de la crisis que despojará a Chile de su 'alma”' (Karmy,

\footnotetext{
16 Aquí San Francisco se refiere al Movimiento Gremial, fundado por Jaime Guzmán en la década del 60, cuyas ideas serán de gran influencia en el régimen de Pinochet, especialmente en torno a la Constitución de 1980. Para este movimiento, puede revisarse Valdivia Ortiz de Zárate (2008).

17 El énfasis en el original.
} 
2017: 102). Pero esto no es exactamente así: Góngora distingue entre el golpe de Estado, que apoya y valora, y el sistema económico, posteriormente implementado, que rechaza de plano.

Por otra parte, y profundizando un poco más en la conexión que ya vimos en García de la Huerta, Karmy sostiene que la tesis gongoriana - según la cual "el Estado crea la nación" - no es original. "Se encuentra de manera explícita en el célebre texto Teología Política [...], de 1922, escrito por el célebre jurista Carl Schmitt" (Karmy, 2017: 102). Esta conexión estaría dada por el hecho de que Schmitt, efectivamente, sostiene que el poder constituyente del Estado apunta a generar "la forma para la vida de un pueblo, no arbitraria coacción por medio de la violencia cualquiera" (Schmitt, 1999: 28).

Sin embargo, surge la pregunta de si, en el marco de una sociedad abierta (liberal y democrática), es normativamente aceptable la tesis de que el Estado crea, de arriba hacia abajo, la nación o el pueblo. ¿Hasta qué punto una noción como esta implica, en la práctica - y así, en efecto, ha ocurrido en no pocos casos-, un ataque directo a la libertad individual y a la diversidad de identidades que puede darse en una sociedad de ese tipo? Prácticamente ninguno de los autores mencionados en este trabajo cuestionan este punto.

Un tercer autor que vale la pena destacar en esta sección es Diego González Cañete, quien se propone atender al "fundamento político e intelectual" del Ensayo histórico (2017: 115). González Cañete pone su vista en la noción de "estatismo", puesto que Góngora defiende la idea de que la función principal del Estado en Chile ha sido, fácticamente, y debería seguir siendo - normativamente hablando-, la de crear o dar vida a la nación. González Cañete señala que el liderazgo que el Estado ejerció en Chile en el periodo posterior a la Independencia puede explicarse por la necesidad de lograr una cohesión institucional en el país, y para así “traspasar al 'pueblo' una virtud republicana antes inexistente” (González Cañete, 2017: 119). Pero, ¿es esta la interpretación del mismo Góngora? ¿Defiende Góngora su tesis solo a partir de una constatación histórica o, en el contexto del régimen militar, lo hacía también a partir de un determinado pensamiento político?

No cabe duda de que, en términos históricos, los Estados ejercieron un importante rol en la construcción de las identidades nacionales, 
especialmente luego de sus procesos autonómicos o de unificación; en América y Europa, respectivamente. En este sentido, generaron lo que Eric Hobsbawm (1917-2012) denomina "tradición inventada", esto es, un conjunto "de prácticas, gobernadas por reglas aceptadas abierta o tácitamente y de naturaleza simbólica o ritual, que buscan inculcar determinados valores o normas de comportamiento por medio de su repetición" (Hobsbawm, 2002: 8).

Sin embargo, una cosa es la constatación (y explicación histórica) del papel de los Estados en las construcciones institucionales y culturales que tuvieron lugar en el siglo XIX, y otra muy distinta es considerar que ellos deberían, permanentemente - cual función normativa-, "crear" las naciones. No ex nihilo, pero al menos partiendo de la base de que es deseable y provechoso que el Estado sea el ente encargado de configurar (y dar cuenta de) la identidad nacional, a la que habrían de subordinarse las identidades individuales o grupales. Este punto, que podría resultar obvio, y en torno al cual las ciencias sociales han derramado bastante tinta en los últimos años, tiende a ser pasado por alto por los comentaristas de Góngora, provenientes de distintos lados del espectro político. ${ }^{18}$

Por otra parte, González Cañete destaca un elemento poco tratado por esos comentaristas: los integrantes de la Juventud Conservadora admiraban un modelo político sustentado en la relevancia de los cuerpos intermedios de la sociedad, entendidos como "estructuras naturales", entre las que se encontrarían la familia, la comuna y la corporación gremial (González Cañete, 2017: 134). Este autor plantea una pregunta interesante: “ $¿$ En qué sentido, no obstante, el socialcristianismo de juventud [de tendencia corporativista] constituyó una fuente de apropiación intelectual para el Góngora historiador?" (González Cañete, 2017: 135).

Sin embargo, esta pregunta podría ampliarse a la influencia del corporativismo en el antiliberalismo permanente de Góngora, y a la persistencia del fascismo católico en su pensamiento político. Ambos ejes

18 Un ejemplo, para el caso de Chile, de alguien que ha cuestionado los relatos que apuntan a defender la existencia de identidades esencialistas, puede verse en Larraín (2001). De hecho, el mismo Larraín sitúa el planteamiento de Góngora dentro de lo que llama "versión militar-racial" de la identidad chilena. 
de su pensamiento parecen haberse extendido a lo largo de toda su vida, desde su juventud hasta el final de sus días. Y el Ensayo histórico no parece constituir una excepción en este sentido.

\section{Conclusión}

Como primer objetivo, este trabajo ha buscado referir algunos debates fundamentales que la figura de Mario Góngora ha generado como pensador político más que como historiador. Como se ha visto, estos debates se han desarrollado con mayor fuerza desde la publicación, en 1981, de su Ensayo histórico. No obstante que algunos de sus comentaristas mencionan algunas conexiones ideológicas de Góngora con el fascismo - no solo católico, sino incluso italiano y alemán-, prácticamente ninguno profundiza en ellas.

Precisamente, y como segundo objetivo de este trabajo, se ha buscado destacar que, aunque en un principio el pensamiento de Góngora pueda parecer ecléctico, por reunir dentro de sí diversas categorías ideológicas, al final del día tiene un marcado componente antiliberal y fascista católico. Esta circunstancia puede percibirse en su rechazo a la democracia representativa y al libre mercado, por supuestamente apuntar a la atomización de la sociedad, y en la nostalgia y valoración de una sociedad tradicional y corporativa, a partir de la cual el Estado podría seguir creando la nación.

Este trabajo sostiene que los autores que han tratado a Góngora como pensador político tienden a pasar por alto o minimizar los ejes fundamentales de sus ideas, su antiliberalismo y fascismo católico. Asimismo, plantea la hipótesis de que la simpatía transversal que, en ellos, ha generado la figura intelectual de Góngora podría explicarse por su antiliberalismo económico, especialmente en el contexto del régimen militar, liderado por Augusto Pinochet.

Por otra parte, y solo con el propósito de mostrar la continuidad del pensamiento de Góngora, es interesante considerar que sus ideas ya estaban presentes mucho antes de la publicación del Ensayo histórico. Por ejemplo, en un ensayo de 1966 Góngora busca armonizar los dos ejes referidos de su pensamiento político.

No deja de ser curioso que su crítica al capitalismo la haya expresado primero en ese texto, en el contexto del gobierno democratacris- 
tiano, liderado por Eduardo Frei Montalva, que se definió como una tercera vía entre socialismo y capitalismo. ${ }^{19}$ Góngora llega a hablar allí de una alianza sui generis entre materialismo capitalista y socialcristianismo. Esto sería así, agrega, porque durante el siglo XIX el socialcristianismo habría representado una reacción contra la burguesía liberal capitalista. Pero ahora, en este ensayo, se lamenta de la pérdida, en el siglo XX, del rasgo corporativo de la sociedad y de la aceptación del liberalismo político y de la democracia (Góngora, 1987: 176). ${ }^{20}$

Pero lo interesante del ensayo de 1966 es su idea de que, pese a la existencia de la democracia liberal, el golpe final a la sociedad tradicional la pondría el capitalismo (en ese momento, no usaba todavía la palabra neoliberalismo). Góngora sostiene que, si bien la ética del capitalismo puede realizarse en países protestantes, con mucha dificultad puede gestarse en la cultura hispanoamericana de carácter católico. La razón es que esa ética requeriría de una mentalidad o ideología social que solo la tradición puede proporcionar. Dice Góngora: "No se trata solamente de crear un grupo que persiga el lucro a través de la empresa", sino que, además, añade, es necesario formar "una convicción de la legitimidad de su existencia" y "una creencia en la eticidad y valor de ese género de vida" (1987: 177). Nada de esto, para él, sería parte de la cultura hispanoamericana, de corte católico, de la que Chile formaría parte. Cabe aquí preguntarse si, dado que para Góngora "el Estado crea la nación", ¿por qué no podría también generar las condiciones para la formación de una sociedad de emprendedores?

De hecho, y como se lo hizo ver Fontaine, Góngora parece haber olvidado el desarrollo capitalista del que Chile fue protagonista durante el siglo XIX, del cual fue parte fundamental el puerto de Valparaíso (Fontaine, 1982). No por nada ese desarrollo capitalista ayuda a explicar la proyección de Chile hacia el desierto de Atacama y, en no menor medida, la misma Guerra del Pacífico contra Perú y Bolivia (18791884). ${ }^{21}$ En otras palabras, la tesis de Góngora, según la cual el Estado habría creado la nación a través de la guerra durante el siglo XIX, no

\footnotetext{
19 Ver "Lo que Chile está realizando. 1965-1968".

20 Este artículo fue originalmente publicado en la revista Dilemas, $\mathrm{N}^{\circ} 2$ (1966).

${ }^{21}$ Esta tesis es fundamentalmente desarrollada por la historiografía peruana de manera casi unánime. Pero también por parte de la chilena, como es el caso de Ortega (2018).
} 
puede fácilmente desligarse de la apertura económica y comercial que el mismo Estado desarrolló durante esa centuria.

En este sentido, y a pesar de que la misma interpretación historiográfica de Góngora sobre el periodo republicano puede ser problematizada, cabe por ahora constatar que los debates que sus ideas políticas han generado siguen todavía abiertos. Falta aún mucho por decir, y este trabajo espera, al menos, haber puesto sobre la mesa algunos vacíos desde los cuales podría seguir dialogándose sobre el pensamiento político de Mario Góngora.

\section{Referencias bibliográficas}

\section{Fuentes primarias}

a) Periódicos y revistas

Guzmán, R. "Mario Góngora, la perspectiva del historiador", La Segun$d a, 7-\mathrm{V}-1982$, pp. 24-25.

\section{Fuentes secundarias}

\section{a) Artículos y capítulos de libros}

Bannister, C. (2012). "José Antonio Primo de Rivera: Catholic Fascism", en A. Quiroga y M. Á. del Arco. Right-Wing Spain in the Civil War Era. Soldiers of God and Apostles of the Fatherland, 1914-45. New York: Continuum International Publishing Group, pp. 91-116.

Fontaine, A. (1982). "Un libro inquietante", en Economía y Sociedad, segunda época, $\mathrm{N}^{\circ} 2$, pp. 313-320.

García de la Huerta, M. (1987). "Nación-Estado y legitimidad en Chile. Reflexiones sobre un libro de Mario Góngora", en Opciones, $\mathrm{N}^{\circ} 57$, pp. 155-167.

Góngora Escobedo, A. (1990). "El Estado en Mario Góngora, una noción de contenido spengleriano", en Historia, vol. 25, pp. 3979.

Góngora, M. (1982). “Respuesta del profesor Góngora”, en Economía y Sociedad, segunda época, $\mathrm{N}^{\circ} 3$, pp. 20-21.

González Cañete, D. (2017). “¿Estatismo como nostalgia? Mario Góngora y la génesis de una tesis polémica", en G. Geraldo y J. C. Vergara (eds.). Mario Góngora: el diálogo continúa. Once 
reflexiones sobre su obra. Santiago de Chile: Historia Chilena, pp. 113-144.

Hobsbawm, E. (2002). "Introducción: la invención de la tradición", en E. Hobsbawm y T. Ranger (editores). La invención de la tradición. Barcelona: Crítica, pp. 7-21.

Karmy, R. (2017). "Teología de la historia. La historiografía de Mario Góngora como una apocalíptica”, en G. Geraldo y J. C. Vergara (eds.). Mario Góngora: el diálogo continúa. Once reflexiones sobre su obra. Santiago de Chile: Historia Chilena, pp. 99-111.

Salazar, G. (1982). "Historiadores, historia, Estado y sociedad. Comentarios críticos en torno al Ensayo histórico sobre la noción del Estado en Chile en los siglos XIX y XX de Mario Góngora", en Nueva Historia, vol. 2, $\mathrm{N}^{\circ}$ 7, pp. 193-200.

Salazar, G. (2017). "Mario Góngora: un precursor de la historia social en Chile", en G. Geraldo y J. C. Vergara (eds.). Mario Góngora: el diálogo continúa. Once reflexiones sobre su obra. Santiago de Chile: Historia Chilena, pp. 33-40.

San Francisco, A. (2017). "El Ensayo histórico sobre la noción del Estado en Chile en los siglos XIX y XX. Una lectura crítica", en G. Geraldo y J. C. Vergara (eds.). Mario Góngora: el diálogo continúa. Once reflexiones sobre su obra. Santiago de Chile: Historia Chilena, pp. 67-90.

Yávar Meza, A. (2017). "Mario Góngora. Aproximaciones al historiador y su obra", en G. Geraldo y J. C. Vergara (eds.). Mario Góngora: el diálogo continúa. Once reflexiones sobre su obra. Santiago de Chile: Historia Chilena, pp. 51-60.

b) Libros

Arancibia Clavel, P. (1995). Mario Góngora en busca de sí mismo. 19151946. Santiago de Chile: Fundación Mario Góngora.

Arancibia Clavel, P., y F. Balart Pérez. (2007). Sergio de Castro. El arquitecto del modelo económico chileno. Santiago de Chile: Libertad y Desarrollo-Fundación Costabal-Editorial Biblioteca Americana.

Bravo Lira, B. (1992). El absolutismo ilustrado en Hispanoamérica, Chile (1760-1860). De Carlos III a Portales y Montt. Santiago de Chile: Editorial Universitaria.

Collier, S. (1977). Ideas y política de la Independencia chilena. Santiago de Chile: Andrés Bello. 
Eyzaguirre, J. (2002). Ideario y ruta de la emancipación chilena. Santiago: Editorial Universitaria.

Geraldo, G. y J. C. Vergara (eds.). (2017). Mario Góngora: el diálogo continúa. Once reflexiones sobre su obra. Santiago de Chile: Historia Chilena.

Góngora, M. (1970). Encomenderos y estancieros. Estudios acerca de la constitución social aristocrática de Chile después de la Conquista, 1580-1660. Valparaíso: Departamento de Historia, Universidad de Chile.

Góngora, M. (1975). Studies in the colonial History of Spanish America. Cambridge: Cambridge University Press.

Góngora, M. (1981). Ensayo histórico sobre la noción del Estado en Chile en los siglos XIX Y XX. Santiago de Chile: Editorial La Ciudad.

Góngora, M. (1987). Civilización de masas y esperanza, y otros ensayos. Santiago de Chile: Editorial Vivaria.

Góngora, M. (2013). Diario. Edición crítica de Leónidas Morales. Santiago de Chile: Editorial Universitaria-Ediciones UC.

Góngora, M. (2016). Tesis. Conflictos Religiosos y Sociales del Estado y la Burguesía en Inglaterra siglos XVII y XVIII. Santiago de Chile: Editorial Universitaria-Ediciones UC.

Holmes, S. (1993). Anatomy of Antiliberalism. Cambridge: Harvard University Press.

Larraín, J. (2001). Identidad chilena. Santiago de Chile: LOM Ediciones.

Ortega, L. (2018). Chile en ruta al capitalismo. Cambio, euforia y depresión, 1850-1880. Santiago de Chile: LOM Ediciones.

Payne, S. G. (1985). Falange. Historia del fascismo español. Madrid: Sarpe.

Rallo, J. R. (2019). El liberalismo. Los 10 principios básicos del orden político liberal. Madrid: Ediciones Deusto.

Schmitt, C. (1982). Teoría de la Constitución. Madrid: Alianza Editorial.

Schmitt, C. (1999). Teología política. Cuatro capítulos sobre el concepto de soberanía. Madrid: Editorial Trotta.

Soto, A. y F. Sánchez (compiladores). (2015). El "Padre" de los Chicago Boys. Arnold Harberger. Santiago de Chile: Centro de Estudios Bicentenario.

Valdivia Ortiz de Zarate, V. (2008). Nacionales y gremialistas. El "parto" de la nueva derecha política, 1964-1973. Santiago de Chile: LOM Ediciones. 
Vial Correa, G. (2009). Cinco siglos de historia. Desde los primeros pobladores hasta el año 2006, tomo 2. Santiago de Chile: Editorial Zig-Zag. 